This is the Pre-Published Version

\title{
Strengthening efficiency of taper ended FRP strips bonded to RC beams
}

\author{
Bo Gao ${ }^{\mathrm{a}}$, Jang-Kyo Kim ${ }^{\mathrm{a} *}$ and Christopher K. Y. Leung ${ }^{\mathrm{b}}$ \\ ${ }^{a}$ Department of Mechanical Engineering and ${ }^{b}$ Department of Civil Engineering \\ Hong Kong University of Science \& Technology, Clear Water Bay, Hong Kong
}

\begin{abstract}
:
External bonding of fiber reinforced plastic (FRP) strips to reinforced concrete (RC) beams has been widely accepted as an effective method for strengthening and rehabilitation of aging civil structures. The FRP strips improve significantly the ultimate flexural strength of RC beams. This paper reports the effectiveness of taper end FRP design in further enhancing the structural performance of strengthened RC beams. The relative performance of taper distance was specifically evaluated in an effort to optimize the FRP strip end geometry for given RC beam dimensions. With rehabilitation of damaged and/or aging structures in mind, precracked RC beams were also studied. The four point bending experiment indicated that the tapered FRP strip end design augmented significantly the ultimate load and mitigated the reduction in beam deflection corresponding to the ultimate load, compared to the beams bonded with constant thickness FRP strips. There was negligible difference in flexural performance between the virgin and precracked RC beams after they were bonded with taper ended FRP strips, indicating that the tapered FRP design concept can be applied to both undamaged and aging/damaged structures.
\end{abstract}

Keywords: Fiber composite; Taper end; Strengthening; Precracked member.

*Corresponding author. Tel: 852-2358 7207; Fax: 852-2358 1543; Email: mejkkim@ust.hk 


\section{Introduction}

On account of deterioration caused by aging under severe environment and poor routine maintenance, as well as the requirements to increase the load carrying capacity due to change in the use of structures, the needs for strengthening and rehabilitation of reinforced concrete (RC) structures are becoming increasingly apparent. Various methods for strengthening and rehabilitation of RC structures have been developed in the past several decades. Amongst these methods, external bonding of fiber reinforced plastic (FRP) strips to the beam tensile face has been widely accepted as an effective and convenient method, because FRPs possess a number of beneficial characteristics including high strength and stiffness, high resistance to corrosion and chemicals, light weight due to low density, as well as reduced maintenance of strengthening system and reduced use of mechanical fixing [1,2].

Typical failure modes of FRP strengthened RC beams can be grouped into seven categories. They are (a) flexural failure by FRP rupture, (b) flexural failure by crushing of compressive concrete, (c) shear failure, (d) concrete cover separation, (e) plate end interfacial debonding, (f) interfacial debonding induced by intermediate flexural crack and (g) interfacial debonding induced by intermediate flexural shear cracks $[3,4]$. Concrete cover separation and various kinds of interfacial debonding are considered premature failure modes that prevent the FRP from achieving its ultimate failure strain. Any means to delay the occurrence of concrete cover separation or interfacial debonding can lead to enhancement in load carrying capacity of the strengthened member.

In an effort to delay the premature failure modes, many measures have been suggested, including the use of end anchors around the FRP strip ends [5], the use of compliant rubber toughened adhesives to bond the FRP strips [6,7], and the termination of FRP strips near the supports [8]. Another potentially useful method for delaying concrete cover separation is the use of FRP strips that are tapered at the ends. In the design of adhesive bond repairs for laminated 
composite structures, tapering has been widely applied to avoid premature failure by reducing the adhesive peel stresses [9-12].

The use of tapered FRP strips to control and reduce the edge stresses and thus to improve the load carrying capacity of various structures has been studied extensively [13-19]. The numerical study on strengthened steel structures [13,14] showed that the tapers with a beveled angle of $45^{\circ}$ reduced the maximum shear and normal stresses by approximately 30\% and $50 \%$ respectively, suggesting the usefulness of tapers in delaying the premature debond failure of CFRP plate. A closed-form analytical model was formulated $[15,16]$ with special emphasis on the effects of adhesive spew-fillet at the FRP edge, vertically prestressed anchoring devices and the adhesive thickness. It was shown that a significant reduction in all edge stress components, including the peel and shear stresses, could be achieved by decreasing the thickness or increasing the width of the FRP strip towards the edge.

An earlier experimental study [17] showed that the ultimate strength of concrete beams strengthened with taper ended FRP strips was 1.9 to 2.4 times higher than that for the unstrengthened control member. However, there was no comparison between the beams with taper ended FRP strips and constant thickness FRP strips. In another study, the strengthened beams without and with FRP tapering (with FRP strip thickness decreasing from $0.8 \mathrm{~mm}$ to 0.2 $\mathrm{mm}$ in four equal steps) exhibited negligible difference in maximum load and the corresponding displacement [18]. No definite conclusion was drawn on the effect of FRP tapers in this preliminary experiment based on just two test samples. In the FIB report on strengthening with FRP [19], tapered FRP strips were suggested as a kind of detailing without providing any detailed information, because of limited research results available on this subject. In summary, there have been significant interests in the use of taper-ended FRP strips for strengthening RC and steel structures. While a substantial progress has been made in the formulation of theoretical analyses to identify beneficial mechanisms and important parameters affecting the performance 
of tapered FRP strips, there has been lack of experimental evidence that can warrant wider applications of this useful concept.

In practice, strengthening and rehabilitation often need to be performed on aging or damaged structures. With this in mind, precracked RC beams have also been studied extensively. While significant research has been carried out on this topic, inconsistent conclusions are drawn due to the large differences in experimental conditions [20-24]. For crack induced debonding, it is generally observed that the strengthening effect for a precracked beam is not significantly different (with no more than $10 \%$ reduction in ultimate load) to that for a non-precracked beam. Results on precracked RC beams strengthened with FRP strips that failed by concrete cover separation, are not available.

The present study forms part of a larger project aiming to enhance the long-term mechanical performance and structural durability of FRP strengthened concrete structures through optimization of material selection and design variables. Following our success in enhancing the load carrying capacity and ductility of strengthened RC beams using epoxy adhesives modified with liquid rubber [6,7], a series of papers are devoted to investigate the RC beams strengthened with tapered FRP strips. This paper is the first of its series, aiming to provide an insight into the comparative structural performance of RC beams with and without tapers based on the four point flexure test. A further study based on numerical analysis and failure diagrams has been performed to optimize the taper distance and end geometries for given RC beam dimensions [25] and thus to confirm the present experimental evidence. Experimental and analytical investigations regarding the influence of tapered FRP strips on interlaminar fracture resistance between the FRP and concrete are also investigated [26].

\section{Experimental Program}

\subsection{Materials}


The materials employed, and the dimensions and geometry applied to produce RC beams were basically the same as those reported previously [6,7]. Two different groups of reinforced concrete beams were cast at different times. The compressive strengths of concrete, measured from cylindrical specimens (100 mm diameter and $200 \mathrm{~mm}$ height), were 47.8 MPa and 62.1 MPa; and the elastic moduli were 32.5 GPa and 37.1 GPa (calculated according to ACI Building Code 318-83), respectively, for the first and second group of specimens. The stirrups and the compressive longitudinal steel rebars were made of mild steel, while the tensile longitudinal rebars were made of hot rolled, high yield steel. The modulus and tensile yield strength of the high yield steel were $200 \mathrm{GPa}$ and $460 \mathrm{MPa}$, respectively, as measured in the tensile test. The carbon fiber reinforced plastic (CFRP) strip used in this work was MRL-T7-200 (supplied by Reno Carbon Fiber), a unidirectional carbon fiber reinforced epoxy prepreg with a nominal tensile strength of $4.2 \mathrm{GPa}$ and a modulus of $235 \mathrm{GPa}$. The adhesive used to bond the CFRP onto the concrete consisted of an epoxy resin (MRL-A3), a primer (MRL-A2) and a hardener (MRL-B2). The primer for bond enhancement was a mixture of epoxy primer and hardener in the ratio of 100:35 by mass. The resin was a mixture of epoxy resin and hardener, also in the ratio of 100:35 by mass.

\subsection{Specimen fabrication and flexural test}

A total of eighteen RC beams were fabricated to study the structural performance of FRP strengthened beams in the four point bending configuration. All RC beams had the same overall cross sectional dimensions, internal longitudinal reinforcement and stirrup arrangements. They were $200 \mathrm{~mm}$ high $\times 150 \mathrm{~mm}$ wide $\times 2000 \mathrm{~mm}$ long, with $25 \mathrm{~mm}$ concrete cover depth. The beams were reinforced with $10 \mathrm{~mm}$ high yield steel rebars on the tension side and $8 \mathrm{~mm}$ mild steel rebars on the compression side. The steel reinforcement ratio was about $0.86 \%$. $8 \mathrm{~mm}$ stirrups were added at a $75 \mathrm{~mm}$ center-to-center spacing as shown in Fig. 1, to over-reinforce 
the member in shear so flexural failure could be assured. Before bonding the FRP strips, the concrete surface on the soffit of the beams was roughened with a jet chisel to remove all laitance and to expose the aggregates. The rough surface was then cleaned with water and compressed air. A primer (MRL-A2), with hardener (MRL-B2), was applied to cover the roughened surface. The CFRP sheets were bonded to the concrete surface using the adhesive consisting of epoxy resin (MRL-A3) and hardener (MRL-B2). Finally, a resin overcoat was applied on top of the CFRP sheets, followed by curing at room temperature for a week.

The FRP strips used were $150 \mathrm{~mm}$ wide, and either $0.44 \mathrm{~mm}$ or $0.66 \mathrm{~mm}$ thick (with four or six layers of FRP sheets) along most of its length. The cut-off point was $20 \mathrm{~mm}$ from each support. Nine different tapered end configurations (Fig. 2) consisting of taper in each layer and every two layers with different taper distances were tested. The taper distance is the length difference between the adjacent FRP layers at the end. The details of external FRP strip reinforcements and taper conditions are summarized in Table 1. The specimens were designated according to the following scheme. The first number indicates the group of specimens. $\mathrm{O}, \mathrm{N}$ and T refer to the cases with no FRP reinforcement, uniform thickness FRP strips and tapered FRP strips, respectively. The number after $\mathrm{N}$ or $\mathrm{T}$ represents the number of CFRP layers. The following two numbers refers to the taper distance. The last number represents the taper condition (1 for taper in each layer, and 2 for taper in every two layers). Finally, for the precracked beams, 'P' is added at the end of the designations.

To precrack some of the beams before the performance of strengthening, a preload was applied. The preload in the present study was set at $39 \mathrm{kN}$, approximately $70 \%$ of yielding load of the control beam (beam 2O). Many small cracks were observed in the tension part of the RC beam upon application of the preload. We believe this level of preloading is quite reasonable because the service load under practical situations is often below the load for steel yielding to occur in the beam. After loading to the pre-determined preload, the member was fully unloaded. The concrete surface was then properly prepared for the bonding of CFRP strips. 
The four point flexural tests of RC beams were performed on an MTS810 universal testing machine with a maximum load capacity of $500 \mathrm{kN}$ under the displacement control mode. The specimen supports consisted of a pin support and a roller support at the two ends. The inner and outer loading spans were $500 \mathrm{~mm}$ and $1500 \mathrm{~mm}$, respectively. Three linear variable displacement transducers (LVDTs) were used to measure the deflection of the beam at the positions of mid span and the two loading points. The load-displacement data were automatically recorded using a data logger.

\section{Results and Discussion}

The summary of ultimate failure loads and the corresponding deflections as well as the failure modes are presented in Table 2. The beams 10 and 20 with no CFRP showed typically ductile flexural responses. After yielding of tensile steel reinforcement, concrete crushing occurred between the loading points due to the high compressive stress. Other samples exhibited concrete cover separation as the principle failure mode, except the beams 2T675-1 and 2T4100-1 that showed interfacial debonding failures. Photographs for beams failed by these two major failure modes are shown in Fig. 3. As a result of strengthening with CFRP strips, there were significant increases in ultimate failure load and reductions in deflection at failure. In the following, the influences of the tapered ends on structural performance of RC beams are shown, and the effects of major geometric and material parameters are discussed separately.

\subsection{Effect of taper ended FRP strips}

To study the effects of taper ended FRP strips in beams without precracks, different taper configurations were applied. The results show that the FRP strips with tapered ends consistently improved the strengthening performance in terms of both load carrying capacity and deflection

at failure (shown in Table 2). The beams 1N6 and 2N6 without tapers in FRP strips exhibited 
ultimate loads of $116.2 \mathrm{kN}$ and $135.9 \mathrm{kN}$ and the deflections at failure of $7.5 \mathrm{~mm}$ and $8.0 \mathrm{~mm}$, respectively. When the FRP strip ends were tapered at a distance of $50 \mathrm{~mm}$ in each layer (i.e. the beams $1 \mathrm{~T} 650-1$ and $2 \mathrm{~T} 650-1$ ), the enhancements of the ultimate load were $19.3 \%$ and $2.2 \%$, respectively, and the corresponding increases of deflection at failure were $29.3 \%$ and $8.8 \%$. For the specimens in the second group, the maximum improvement due to taper was achieved by the beam 2T6100-2, which had a taper distance of $100 \mathrm{~mm}$ in every two layers. The increases were $7.9 \%$ in load capacity and $23.8 \%$ in deflection at failure.

The efficiency of tapered ends in improving the strengthening performance of FRP strips was attributed to reduced stress concentrations at the end of FRP strips. The reduced stress can delay the crack initiation from the FRP strip ends, which in turn contributed to increasing the load capacity of RC beams.

\subsection{Effects of taper distance}

Fig. 4 presents that the taper distance (the length difference between the adjacent FRP layers at the end) had a significant influence on the strengthening performance of non-precracked RC beams.

In the second group of non-precracked specimens, taper distances of $0 \mathrm{~mm}, 25 \mathrm{~mm}, 50$ $\mathrm{mm}$ and $75 \mathrm{~mm}$ (for corresponding beams 2N6, 2T625-1, 2T650-1 and 2T675-1, respectively) were studied for strips made of six layers of FRP. When the taper distance was increased from $25 \mathrm{~mm}(2 \mathrm{~T} 625-1)$ to $50 \mathrm{~mm}(2 \mathrm{~T} 650-1)$, the enhancements in ultimate load and corresponding deflection compared to the beam without taper (2N6) were from $1.1 \%$ to $2.7 \%$ and from $6.3 \%$ to 8.8\%, respectively. However, a further increase in taper distance to $75 \mathrm{~mm}$ (2T675-1) deteriorated the enhancements in strengthening and ductility performance (with a negligible increase in ultimate load by $1 \%$ and corresponding deflection by $5 \%$, compared to the beam without taper). 
Similarly, in the second group of non-precracked specimens, taper distances of $0 \mathrm{~mm}, 50$ $\mathrm{mm}$ and $100 \mathrm{~mm}$ (for corresponding specimen numbers, 2N4, 2T450-1 and 2T4100-1, respectively) were studied for strips made of four layers of FRP. When the taper distance was 50 mm (the beam 2T450-1), the load capacity and deflection at failure improved by 3.3\% and 7.6\%, compared to the beam without taper (2N4). When the taper distance was increased to 100 mm (2T4100-1), the ameliorating effect of taper completely vanished and the strengthening performance degraded (with the reductions in ultimate load and corresponding deflection by about $2 \%$ each) in comparison to the beam without taper (2N4).

In theory, the longer the taper distance in the FRP strips used, the more significant should be the stress reductions at the end of FRP strips. It is envisaged, therefore, that the strengthening performance of RC beams should be further improved when a longer taper distance is applied. However, this did not happen in practice as described above. It should be noted that the taper is a 'local' design variable to optimize the strengthening performance, and the application of taper must be limited in the vicinity of the FRP strip end. Therefore, if the tapered region is beyond a certain optimal distance (i.e. the taper distance being longer than a critical value), the performance enhancement due to tapered FRP strip ends may decrease and even vanish completely (as shown for the beam 2T4100-1 with FRP strips having a taper distance $100 \mathrm{~mm}$ ). Associated with the degrading performance due to the long taper distance was the transition of failure mode from concrete cover separation to FRP interfacial debonding. This means that the excessive taper distance may induce the loss of load carrying capacity of the whole beam, and the use of tapered FRP strip is no longer a 'local' design. In fact, from the interfacial debonding model [3], the ultimate debonding force of a FRP strip decreases with its thickness. When interfacial debonding failure dominates, since a long taper distance represents a lower equivalent FRP strip thickness, it may decrease the load capacity. A careful selection of taper variables is of paramount importance if a maximum strengthening performance is to be attained in practical design. 


\subsection{Effect of concrete strength}

The strengths of the concrete produced in two different groups were different. The increase in concrete strength from 47.8 $\mathrm{MPa}$ to $62.1 \mathrm{MPa}$ resulted in the improvements in ultimate strength and corresponding displacement from $68.6 \mathrm{kN}$ and $19.0 \mathrm{~mm}$ (for RC beam 1O) to $71.3 \mathrm{kN}$ and $27.8 \mathrm{~mm}$ (for beam 2O), respectively. When non-tapered FRP strips were bonded to the RC beams, the enhancements of $17 \%$ in maximum load and $6.7 \%$ in midpoint displacement at failure were noted for the beam 2N6 over the beam 1N6 due to the higher concrete strength. However, when the taper ended FRP strips were bonded, the benefits of stronger concrete material completely vanished, or even resulted in a marginally negative influence: the beam 2T650-1 with a higher concrete strength showed an increase of only $1 \%$ in maximum load with a concomitant reduction of $10 \%$ in corresponding displacement compared to the beam $1 \mathrm{~T} 650-1$ with a lower concrete strength. This observation suggests that the effect of concrete strength on structural performance of RC beams diminished when the beams were strengthened with taper ended FRP strips. In other words, the taper end FRP design augments the efficiency of strengthening by FRP strips, while abating the difference in inherent properties of concrete. In fact, this finding has been proved by finite element method (FEM). The detailed discussion is presented in another paper [21], and it is briefly shown in the following.

With the commercial code ANSYS 5.7, a model comprising a FRP strip bonded with an adhesive layer to a RC beam subjected to four point bending was built to simulate the actual test conditions. The steel rebar was modeled as one-dimensional link elements, while eight-node plane stress elements were used for all the other components. To ensure sufficient accuracy of the results the elements in the vicinity of FRP strip ends were refined to capture the concentrated stresses. All components used in the model were assumed isotropic and linear elastic, and all interfaces among different materials were perfectly bonded. The effect of 
concrete strength can be shown by varying the corresponding elastic modulus of elements in the FEM models. The higher the concrete strength, the higher the elastic modulus used in the FEM model. The results showed that under the same loading conditions, for the beams with constant thickness FRP strips, a higher concrete strength gave rise to a principal stress reduction at the end of FRP strips of 5.7\% (2N6 compared to 1N6); in comparison, for the beams with taper ended FRP strips, only 3.2\% principal stress reduction was obtained as a result of the higher concrete strength and elastic modulus (2T650-1 compared to 1T650-1). Since all FRP strengthened RC beams tested in this study failed by concrete cover separation, the principal stress at the end of FRP strips was considered as the most dominant stress component that initiated the failure. Hence, the principal stress reduction should result in the increase of load capacity. Consequently, the lower reduction in principal stress for the beams with taper ended FRP strips (3.2\% compared to $5.7 \%$ for the beams without tapering) should lead to a smaller improvement on load capacity. This is in agreement with the experimental results. A practical implication is that with taper ended FRP strip reinforcements, the quality of concrete becomes a less important factor for determining the flexural performance of beams. Therefore, if one attempts to optimize the efficiency of FRP to strengthen RC beams, the tapered end is a very useful design concept to be considered. In addition, the tapered end concept is also an attractive alternative in terms of material cost reduction as less of the expensive CFRP prepreg is employed. For example, the beam 1T650-1 with six steps of taper can reduce the total consumption of FRP prepregs by about 17\% compared to the beam 1N6 without taper.

\subsection{Comparison between non-precracked and precracked beams}

A comparative study was carried out using the RC beams that were precracked at a flexural load approximately $70 \%$ of that corresponding to yielding of the beam. The precracked beams were strengthened using six or four layers of FRP strips of a constant thickness (designated as 2N6P 
and 2N4P, respectively). The load-displacement curves obtained in four point bending of these beams are shown in Fig. 5, indicating that the strengthening performance of the precracked beams was essentially the same as the non-precracked beams. The beam 2N6 without precracks gave the ultimate load of $135.9 \mathrm{kN}$ and corresponding deflection of $8.0 \mathrm{~mm}$. Meanwhile, the beam 2N6P with precracks exhibited an ultimate load of $132 \mathrm{kN}$ and a corresponding deflection of $8.2 \mathrm{~mm}$. When comparing the beams strengthened with 4 layers of FRP strips (between 2N4P and beam 2N4), there were negligible differences in loading capacity and deflection at failure. Overall, the differences in load carrying capacity and deflection at failure between the beams with and without precracks after FRP strengthening were at most 3\%.

A similar comparative study was also conducted using the RC beams that were precracked and strengthened with taper ended FRP strips. The load-displacement curves obtained in bending of these beams are shown in Fig. 6, and the major results are summarized in Table 2. Similar to the beams strengthened with FRP strips of constant thickness, there were little differences in ultimate load and deflection at failure between the precracked and nonprecracked beams strengthened by taper ended FRP strips. An interesting observation was that the tapered FRP strip ends in precracked beams could also improve the ultimate load and the deflection at failure. The beams 2N6P and 2N4P without tapers showed ultimate loads of 132 $\mathrm{kN}$ and $130 \mathrm{kN}$ and the deflections at failure of $8.2 \mathrm{~mm}$ and $10.8 \mathrm{~mm}$, respectively. When the FRP strips were tapered at a distance of $50 \mathrm{~mm}$ in each layer (i.e. beams 2T650-1P and 2T4501P), there were consistent enhancements in ultimate load and corresponding deflection (3.6\% and 3.7\%, respectively, for beam 2T650-1P, and 4.4\% and 6.5\%, respectively, for beam 2T4501P) compared to the former beams. In addition, the maximum improvement due to taper was achieved by the beam 2T6100-2P, which had a taper distance of $100 \mathrm{~mm}$ in every two layers. The increases compared to the beam 2N6P were 9.7\% in load capacity and $19.5 \%$ in deflection at failure. Therefore, it can be said that the taper ended FRP strips could enhance the strengthening performance in terms of load capacity and ductility, whether the RC beams were 
precracked or not. A practical implication is that this design concept can be applied to both undamaged and aging/damaged beams.

\section{Concluding Remarks}

The taper end design concept has been successfully applied to further enhance the strengthening effect of FRP strips that are bonded to RC beam structures. The following can be highlighted from the experimental study.

(1) The taper ended FRP strips enhanced the load carrying capacity and mitigated the reduction in the corresponding deflection, compared to the beams bonded with FRP strips of a constant thickness. There were little differences in flexural performance between the beams with and without precracks. In both cases, the strengthening effect of taper ended FRP strips was better than that with FRP strips of uniform thickness. This observation suggests that the taper end design concept can be applied to both damaged and damaged/aging structures.

(2) There exists an optimal taper distance to obtain the maximum strengthening effect for given dimensions and properties of the beam. When the taper distance was increased from 25 to 50 $\mathrm{mm}$, the strengthening performance improved by 3 to $9 \%$ compared to the beams without taper, depending on the number of FRP layers. A further increase in taper distance to $100 \mathrm{~mm}$ deteriorated the strengthening effect of FRP strips. Further research is required to optimize the various taper design variables.

(3) Within the accuracy of test results using limited number of specimens, the RC beams made from concretes of different strengths exhibited similar structural performance when the beams were strengthened with taper ended FRP strips.

\section{Acknowledgements}


The Research Grants Council of the Hong Kong SAR (Project No. HKUST 6050/99E), provided the financial support of this work. The authors wish to thank the Construction Materials Laboratory and Advanced Engineering Materials Facility (AEMF) in HKUST for their technical supports. Part of the paper has been presented in $4^{\text {th }}$ International Conference on Advanced Composite Materials in Bridges and Structures (ACMBS-IV), Calgary, Canada, in July 2004.

\section{References}

1. Buyukozturk O, Hearing B. Failure behaviour of precracked concrete beams retrofitted with FRP. J Compos Constr 1998; 2(3): 138-144.

2. Saadatmanesh H, Malek AM. Design Guidelines for Strengthening of RC Beam with FRP Plates. J Compos Constr 1998; 2(4): 158-164.

3. Teng JG, Chen JF, Smith ST, Lam L. FRP-Strengthened RC Structures, John Wiley \& Sons, Chichester. 2002.

4. Smith ST, Teng JG. FRP-strengthened RC beams. I: review of debonding strength models. Eng Struc 2002; 24: 385-395.

5. Garden HN, Hollaway LC. An experimental study of the influence of plate end anchorage of carbon fibre composite plates used to strengthen reinforced concrete beams. Compos Struct 1998; 42: 175-188.

6. Gao B, Kim JK and Leung CKY. Effects of rubber modifier on mechanical properties of interface between CFRP and concrete. Compos Sci Technol 2003; 63: 883-892.

7. Gao B, Kim JK and Leung CKY. Experimental study on RC beams with FRP strips bonded with rubber modified resins. Compos Sci Technol 2004; 64: 2557-2564.

8. El-Mihilmy MT, Tedesco JW. Prediction of anchorage failure for reinforced concrete beams strengthened with fiber-reinforced polymer plates. ACI Struct J 2001; 98(3): 301-314.

9. Hart-Smith LJ. Designing to minimize peel stresses in adhesive joints. ASTM STP 876 1985; 238-266.

10. Vinson JR, Sierakowski RL. The behavior of structures composed of composite materials, Kluwer, Dordrecht, The Netherlands. 1987.

11. Baker AA, Jones R. Bonded Repair of Aircraft Structures, Dordrecht: M. Nijhoff. 1998. 
12. Chalkley P, Baker A. Development of a generic repair joint for certification of bonded composite repairs. Int J Adhes Adhes 1999; 19: 121-132.

13. Miller TC, Chajes MJ, Mertz DR, Hastings JN. Strengthening of a steel bridge girder using CFRP plates. J Bridge Eng 2001; 6(6): 514-522.

14. Deng J, Lee MMK, Moy SSJ. Stress analysis of steel beams reinforced with a bonded CFRP plate. Compos Struct 2004; 65: 205-215.

15. Rabinovitch $\mathrm{O}$ and Frostig Y. On edge stresses control in strengthened RC beams with FRP strips: adhesive layer profile effect. J Struc Eng 2001; 127: 317-325.

16. Rabinovitch $\mathrm{O}$ and Frostig Y. High order approach for the control of edge stresses in RC beams strengthened with FRP strips. J Struc Eng 2001; 127: 799-809.

17. Takeda K, Mitsui Y, Murakami K. Flexural behaviour of reinforced concrete beams strengthened with carbon fibre sheets. Compos Part A 1996; 27: 981-987.

18. Hollaway LC, Leeming MB. Strengthening of Reinforced Concrete Structures, Woodhead Publishing Ltd and CRC Press LLC, Cambridge, England. 1999.

19. International Federation for Structural Concrete (FIB). Externally bonded FRP reinforcement for RC structures, 2001.

20. Sharif A, Alsulaimani GJ, Ghaleb BN. Strengthening of initially loaded reinforced concrete beams using FRP plates. ACI Struct J 1994; 91: 160-168.

21. Arduini M, Nanni A. Behavior of precracked RC beams strengthened with carbon FRP sheets. J Compos Constr 1997; 1: 63-70.

22. Bonacci JF, Maalej M. Externally bonded fibre-reinforced polymer for rehabilitation of corrosion damaged concrete beams. ACI Struct J 2000; 97: 703-711.

23. Shahawy M, Chaallal O, Beitelman TE, EL-Saad A. Flexural strengthening with carbon fiber reinforced polymer composites of preloaded full scale girders. ACI Struct J 2001; 98: 735742.

24. Avril S, Vautrin A, Hamelin P. Mechanical behavior of cracked beams strengthened wit composite: application of a full-field measurement method. Mater Struct 2003; 36: 379-385.

25. Gao B, Kim JK, Leung CKY. Optimization of taper end design for FRP strips bonded to RC beams. Compos Sci Technol 2006; 66: in press.

26. Gao B, Kim JK, Leung CKY. Effect of tapered FRP sheets on interlaminar fracture behaviour of FRP-concrete interface. Compos Part A 2006; 37: in press. 


\section{Figure Captions}

Fig. 1: Dimensions of the FRP strengthened reinforced concrete beam.

Fig. 2: Configurations of various tapered ends of FRP strips.

Fig. 3: Photographs of FRP strengthened RC beams failed by (a) concrete cover separation and (b) interfacial debonding.

Fig. 4: Load vs displacement responses of RC beams strengthened with 4 and 6 layers of FRP strips with various taper distances.

Fig. 5: Load vs displacement responses of RC beams strengthened with constant thickness FRP strips with and without preloading.

Fig. 6: Load vs displacement responses of precracked RC beams strengthened with taper ended FRP strips. 


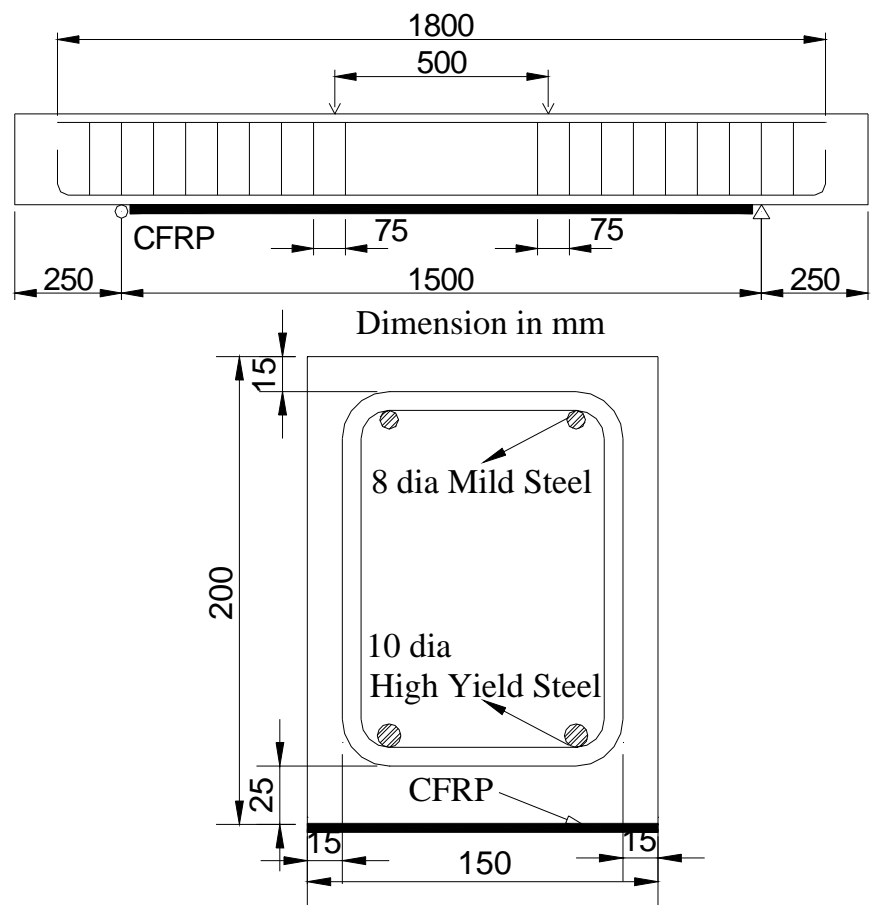

Fig. 1. Dimensions of the FRP strengthened reinforced concrete beam. 


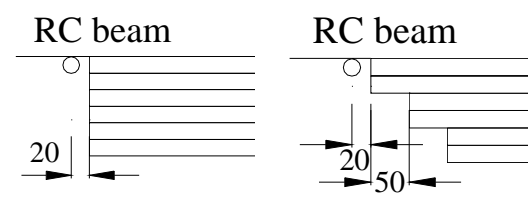

$\begin{array}{ll}\text { (a) } 1 \mathrm{~N} 6,2 \mathrm{~N} 6,2 \mathrm{~N} 6 \mathrm{P} & \text { (b) } 1 \mathrm{~T} 650-2\end{array}$

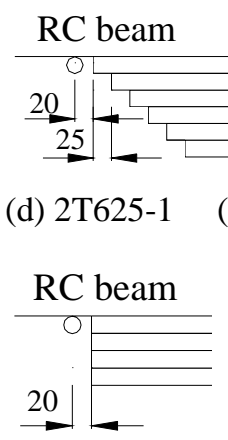

(g) 2N4, 2N4P
RC beam

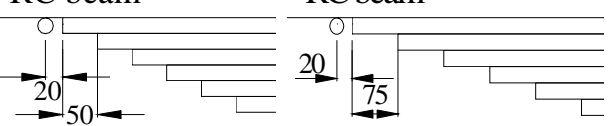

$\begin{array}{ll}\text { (e) } 1 \mathrm{~T} 650-1,2 \mathrm{~T} 650-1,2 \mathrm{~T} 650-1 \mathrm{P} & \text { (f) } 2 \mathrm{~T} 675-1\end{array}$

Fig. 2. Configurations of various tapered ends of FRP strips. 


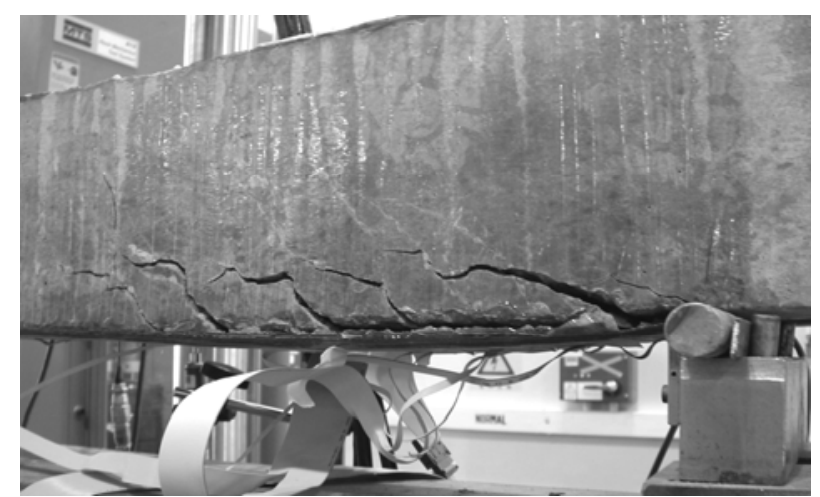

(a)

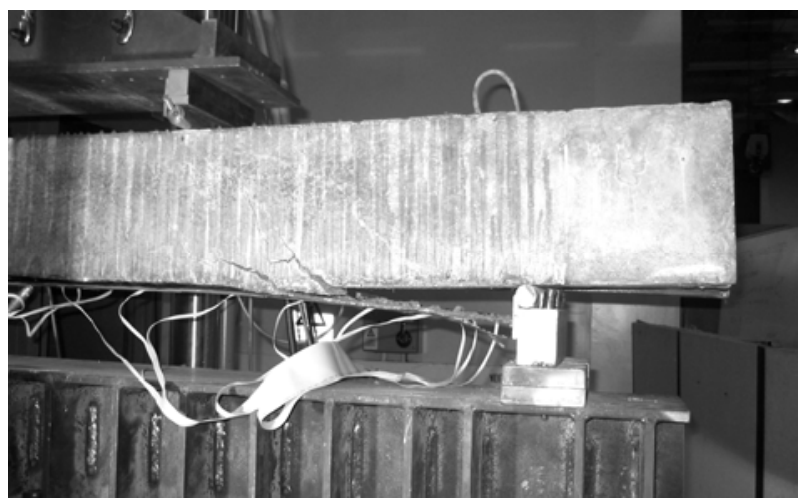

(b)

Fig. 3. Photographs of FRP strengthened RC beams failed by (a) concrete cover separation and (b) interfacial debonding. 


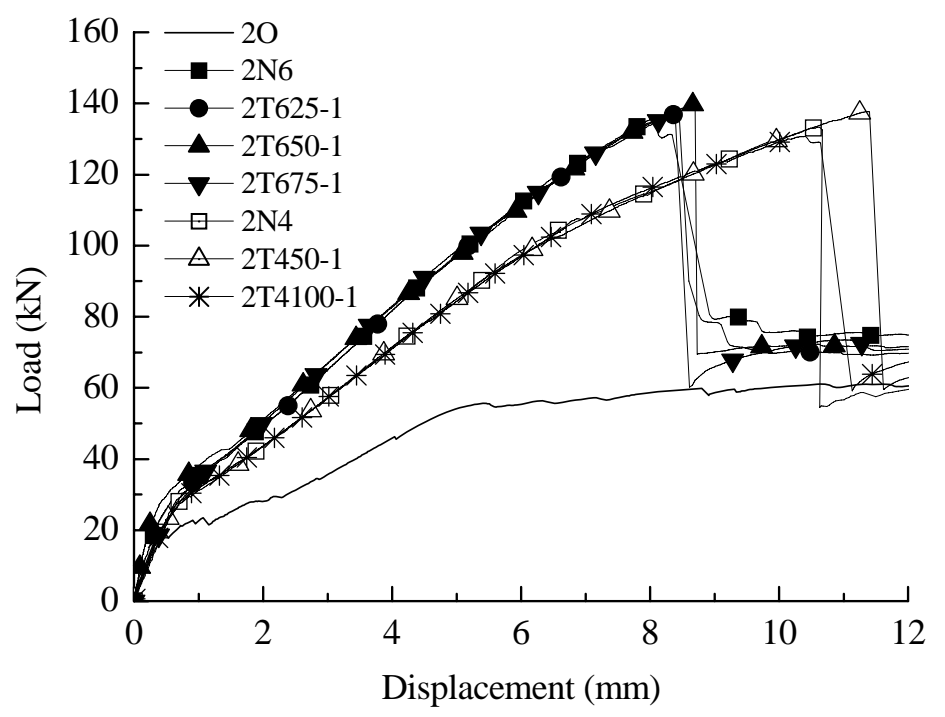

Fig. 4. Load vs displacement responses of RC beams strengthened with 4 and 6 layers of FRP strips with various taper distances. 


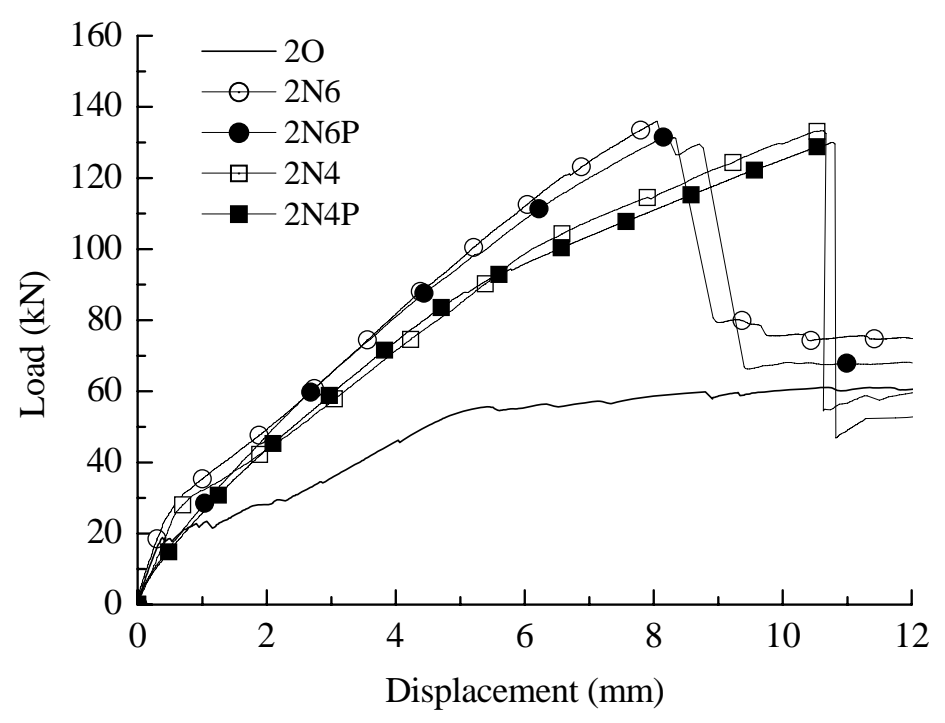

Fig. 5. Load vs displacement responses of RC beams strengthened with constant thickness FRP strips with and without preloading. 


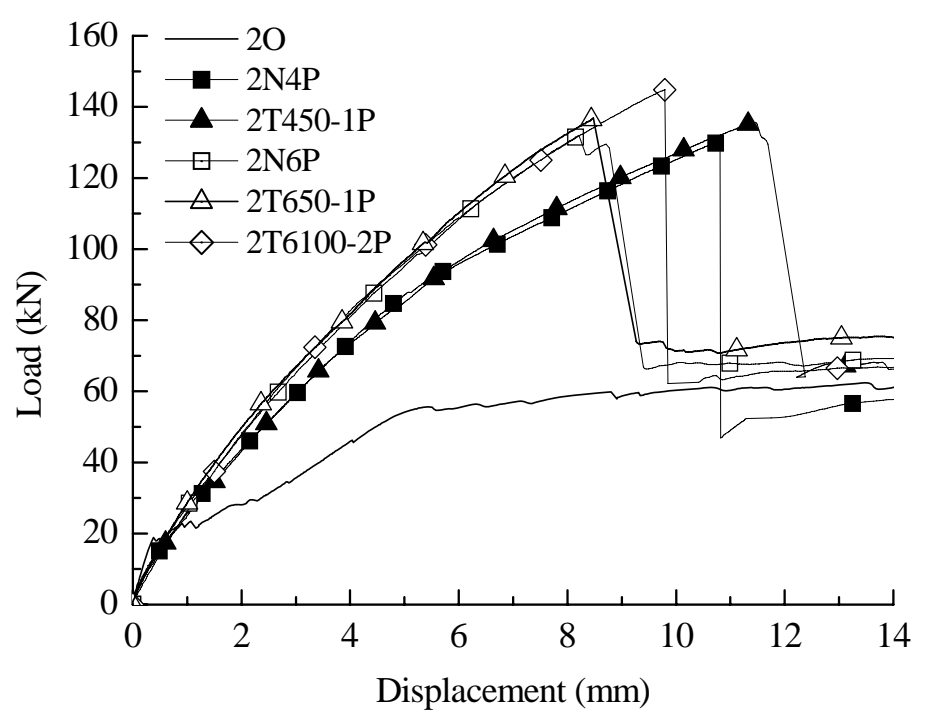

Fig. 6. Load vs displacement responses of precracked RC beams strengthened with taper ended FRP strips. 
Table 1. Specimen designation

\begin{tabular}{clllll}
\hline Beam designation & $\begin{array}{l}\text { Concrete } \\
\text { strength } \\
(\mathrm{MPa})\end{array}$ & $\begin{array}{l}\text { Thickness } \\
\text { of FRP } \\
(\mathrm{mm})\end{array}$ & $\begin{array}{l}\text { Taper condition } \\
\text { 1O }\end{array}$ & $\begin{array}{l}\text { Taper } \\
\text { distance } \\
(\mathrm{mm})\end{array}$ & $\begin{array}{l}\text { Preload } \\
\text { applied }\end{array}$ \\
\hline $1^{\text {st }}$ group & - & - & - & No \\
1N6 & 47.8 & 0.66 & No taper & - & No \\
1T650-1 & 47.8 & 0.66 & Taper in every layer & 50 & No \\
1T650-2 & 47.8 & 0.66 & Taper in every 2 layers 50 & No \\
\hline $2^{\text {nd }}$ group 2O & 62.1 & - & - & - & No \\
2N6 & 62.1 & 0.66 & No taper & - & No \\
2T625-1 & 62.1 & 0.66 & Taper in every layer & 25 & No \\
2T650-1 & 62.1 & 0.66 & Taper in every layer & 50 & No \\
2T675-1 & 62.1 & 0.66 & Taper in every layer & 75 & No \\
2T6100-2 & 62.1 & 0.66 & Taper in every 2 layers 100 & No \\
\hline 2N6P & 62.1 & 0.66 & No taper & - & Yes \\
2T650-1P & 62.1 & 0.66 & Taper in every layer & 50 & Yes \\
2T6100-2P 62.1 & 0.66 & Taper in every 2 layers 100 & Yes \\
\hline 2N4 & 62.1 & 0.44 & No taper & - & No \\
2T450-1 & 62.1 & 0.44 & Taper in every layer & 50 & No \\
2T4100-1 & 62.1 & 0.44 & Taper in every layer & 100 & No \\
\hline 2N4P & 62.1 & 0.44 & No taper & - & Yes \\
2T450-1P & 62.1 & 0.44 & Taper in every layer & 50 & Yes \\
\hline
\end{tabular}


Table 2. Summary of four point bending test results

\begin{tabular}{|c|c|c|c|c|}
\hline \multicolumn{2}{|c|}{ Beam designation } & \multicolumn{2}{|c|}{$\begin{array}{l}\text { Maximum load Deflection at } \\
(\mathrm{kN}) \\
\text { failure (mm) }\end{array}$} & Failure mode \\
\hline \multirow[t]{4}{*}{$1^{\text {st }}$ group } & 10 & 68.6 & 19.0 & $\begin{array}{l}\text { Flexural failure by crushing of } \\
\text { compressive concrete }\end{array}$ \\
\hline & $1 \mathrm{~N} 6$ & 116.2 & 7.5 & Concrete cover separation \\
\hline & $1 \mathrm{~T} 650-1$ & 138.6 & 9.7 & Concrete cover separation \\
\hline & $1 \mathrm{~T} 650-2$ & 130.2 & 8.8 & Concrete cover separation \\
\hline \multirow[t]{14}{*}{$2^{\text {nd }}$ group } & $2 \mathrm{O}$ & 71.3 & 27.8 & $\begin{array}{l}\text { Flexural failure by crushing of } \\
\text { compressive concrete }\end{array}$ \\
\hline & 2N6 & 135.9 & 8.0 & Concrete cover separation \\
\hline & 2T625-1 & 137.4 & 8.5 & Concrete cover separation \\
\hline & 2 T650-1 & 139.6 & 8.7 & Concrete cover separation \\
\hline & $2 \mathrm{~T} 675-1$ & 137.2 & 8.4 & Interfacial debonding \\
\hline & 2T6100-2 & 146.6 & 9.9 & Concrete cover separation \\
\hline & $2 \mathrm{~N} 6 \mathrm{P}$ & 132.0 & 8.2 & Concrete cover separation \\
\hline & 2T650-1P & 136.8 & 8.5 & Concrete cover separation \\
\hline & 2T6100-2P & 144.8 & 9.8 & Concrete cover separation \\
\hline & $2 \mathrm{~N} 4$ & 133.3 & 10.6 & Concrete cover separation \\
\hline & $2 \mathrm{~T} 450-1$ & 137.7 & 11.4 & Concrete cover separation \\
\hline & 2T4100-1 & 130.7 & 10.4 & Interfacial debonding \\
\hline & $2 \mathrm{~N} 4 \mathrm{P}$ & 130.0 & 10.8 & Concrete cover separation \\
\hline & 2T450-1P & 135.7 & 11.5 & Concrete cover separation \\
\hline
\end{tabular}

